\title{
Procedimentos para uma cena mais precisa
}

\author{
Eduardo Tessari Coutinho'
}

\section{Resumo}

O artigo apresenta o resultado de anos da prática teatral do pesquisador, que foram organizadas em seu doutorado. A partir de princípios da mímica, como decupagem e economia de movimento, são apresentados procedimentos práticos que ajudam ao ator a ter consciência de suas ações. Este processo possibilita ao ator o desenvolvimento de uma dramaturgia corporal, tornando sua atuação mais precisa e a cena mais limpa.

Palavras-chaves: Ator, Mímica, Dramaturgia Corporal.

\section{Abstract}

The paper presents the result of years of the researcher's theatrical practice, which were organized on his doctorate. Starting from principles of mime as decoupage and economy of movement, practical procedures are presented in order to help the actor be aware of his actions. This process enables the actor developing a body dramaturgy, making his.

Keywords: Actor, Mime, Body Dramaturgy performance more precise and the scene cleaner.

\section{Introdução}

A minha prática de utilizar os princípios da mímica como uma metodologia de ator começou alguns anos antes de entrar na universidade. Chamo de metodologia de ator e não do ator, em consonância com o conceito de Etienne Decroux "O teatro é a arte de ator” (DECROUX, 1963, p. 41), que Luís Otávio Burnier bem explicou em seu livro:

Ele se refere a uma arte que emana do ator, algo que lhe é ontológico, próprio de sua pessoa-artista, do "ser ator". E não à arte do ator, pois ela não the pertence, ele não é seu dono, mas é quem a concebe e realiza. (BURNIER, 2011, p. 18)

Mas, foi no doutorado, depois de mais de uma década experimentando e com a visão desenvolvida no mestrado, que resolvi organizá-la como material de pesquisa.

\footnotetext{
${ }_{1}^{1}$ Possui graduação em Engenharia Civil pela Escola de Engenharia de São Carlos, da Universidade de São Paulo (1982), mestrado em Artes pela Universidade de São Paulo (1993) e doutorado em Artes pela Universidade de São Paulo (2000). Atualmente é professor doutor do Departamento de Artes Cênicas, da Escola de Comunicações e Artes, da Universidade de São Paulo. É vice-coordenador do grupo de pesquisa CEPECA, do Depto. Artes Cênicas da ECA-USP. Tem experiência na área de Artes, com ênfase em Mímica, atuando principalmente nos seguintes temas: teatro, mímica, ator, teatro fisico, improvisação e comunicação corporal. Além da atividade artística, desenvolve também trabalhos em parceria com pesquisadores das áreas de cidadania e de saúde.
} 
Como a pesquisa transcendia os muros da universidade, resolvi colocar o relato de três artistas que haviam trabalhado comigo, vivenciando os procedimentos. $\mathrm{Na}$ categoria de atuação Rosi Campos, premiada atriz², que trabalhou comigo na peça "Você Vai Ver O Que Você Vai Ver", direção de Gabriel Villela, em 1989. Na categoria de direção, Carlos Alberto Soffredini, com quem trabalhei como diretor corporal por 13 anos, até 1997, em sete montagens e uma inacabada. Na categoria de aluna, Juliana Jardim, que vivenciou a metodologia na peça "Esperando Godot", realizado só com atrizes, em 1995. Foi a sua montagem de formatura no bacharelado em Interpretação Teatral, no Departamento de Artes Cênicas da ECA - USP. Este espetáculo foi dirigido por Robson Corrêa de Camargo, hoje professor na Universidade Federal de Goiás, no qual eu apliquei os procedimentos na remontagem para a participação na Mostra Regional no FILO - Festival de Teatro de Londrina, de 1996.

Mas o conteúdo principal do meu doutorado foi a aplicação dos procedimentos em uma montagem teatral que chamei de didática, isto é, onde as escolhas são feitas para evidenciar o objeto de pesquisa. Escolhi a peça "O Pedestre", de Ray Bradbury, por alguns motivos. O primeiro por ter apenas dois atores, depois por ser um texto curto e, por fim, por ser um texto em que as personagens passam mais de $60 \%$ da peça apenas andando e conversando. Este desafio, tornar uma peça baseada na palavra em uma montagem com riqueza de ações físicas, me interessava. Foram meus atores Eduardo Leão, aluno formado pelo CAC - Departamento de Artes Cênicas, e Roberto Leite, Aluno formado pela EAD - Escola de Artes Dramáticas, ambas as escolas da ECA. René Piazentin, então aluno de bacharelado em direção teatral no CAC-ECA, assumiu comigo a direção. A iniciativa de convidar René para dividir a direção, encarregando-o da encenação, possibilitou-me uma concentração maior nos atores. Na primeira etapa, em que os atores criaram a base do espetáculo, a direção ficou mais sob a responsabilidade de René. Assumi a direção no momento de aplicar os procedimentos.

Para a banca do doutorado foi entregue, além da parte escrita, um vídeo contendo algumas cenas gravadas antes e depois de aplicados os procedimentos, nomeando qual o principal procedimento envolvido naquele trecho. A banca, na defesa, assistiu à apresentação da peça, para poder verificar a potência do resultado teatral.

A seguir apresentarei o objeto desta minha pesquisa: os procedimentos que levam à consciência das ações e consequente precisão da representação e limpeza da cena.

${ }^{2}$ Só com esta peça recebeu o prêmio de melhor atriz no Shell, Mambembe e APETESP. 
A minha atitude é de ser um espelho do ator, de me colocar no lugar de quem quer problematizar todas as informações que os atores estão se propondo a expressar. Essa minha postura tem por objetivo a busca que o ator tenha consciência do que comunica, levando-o a fazer escolhas mais potentes. Isto acaba exigindo ajustes tanto na atuação, quanto na direção.

\section{Procedimentos}

O principal procedimento é a decupagem ${ }^{3}$ das ações. É o procedimento de separar intenção por intenção, definindo uma ação para cada intenção. A decupagem possibilita a consciência de cada passo da cena, por parte do ator, levando-o a entender que primeiro vem uma determinada ação, porque é ela que leva à seguinte, e assim por diante. Portanto, o ator não decora a sequência das ações, mas entende a lógica que ele mesmo propôs para aquela sequência ${ }^{4}$. Ele é aplicado na fase final da montagem, quando os atores já estão seguros de que sabem o que estão representando. Peço para o ator me explicar o que ele quer contar naquele pequeno trecho de cena. Esse trecho pode ser um pedaço de fala, uma fala inteira, mais de uma fala ou, ainda, um trecho sem fala.

Mas, às vezes, o ator não percebe que aquela ação precisa ser melhor desenvolvida, ou então, pode acontecer de ele nunca ter vivenciado aquela ação para poder reproduzi-la. Este foi o caso de Juliana Jardim que, em seu relato em meu doutorado, conta de um ensaio marcante da peça Esperando Godot, em que fazia uma personagem masculina. Ela descreve como eu a ensinei a fazer xixi:

Bom, ele tem problema na bexiga. Não era 'oh, dói a bexiga', você não foi para nada disso. Primeira coisa: pegar a mão e abrir o zíper. 'Abre o zíper. Tem dor? Prende em algum lugar? Não prende? Como que é? Tem alguma coisa por baixo?'. Tudo muito físico, assim. 'Ah, abre o zíper; ombro; respirou; como que faz? A cabeça; olha; baixou a cabeça para olhar?'. 'Não?', 'Na hora que abre o zíper não olha? Você quer olhar?' - e você está deixando todas essas opções para mim; em nenhum momento você falou: 'Abaixa a cabeça, põe a mão...' - nenhum momento. Isso que é o mais legal. Nem nunca você vai e faz. (COUTINHO, 2000, p. 83)

O outro procedimento é chamado de desenho da respiração. A mudança de intenção tem relação com a respiração. Quando inspiramos somos preenchidos com a

\footnotetext{
${ }^{3}$ Decupagem: tradução livre do francês decoupage, do verbo découper, que quer dizer cortar, talhar, trinchar, desenhar.

${ }^{4}$ No caso de um texto sem a lógica aristotélica da ação e reação, como no teatro do absurdo, descobre-se a intenção de cada momento sem a conexão com o momento seguinte, e o atuar vai contando cada ideia na sua sequência, a partir de conexões que o ato cria para facilitar a sua memorização.
} 
nova intenção que, portanto, aparece inteira na expiração conexa, isto é, no momento da ação (verbal e corporal). Os atores fazem o seguinte exercício: a cada mudança de intenção, eles ficam atentos para, na última expiração, jogar fora a intenção vigente. Ao inspirar, eles devem trazer a nova intenção junto com a respiração. Na primeira vez proponho que o ator deva repetir a respiração até estar preenchido inteiramente com o novo impulso, e apenas com ele, para então agir. Assim o ator pode encontrar a medida de cada impulso, relacionado com a intenção, antes de agir. Encontrado, o corpo registra a exata medida de cada impulso específico e particular de cada ator.

Este procedimento ajuda o ator a não carregar a intenção pertinente a uma cena anterior para a seguinte, porque esta contaminação cria uma "sujeira" na comunicação. Associado à decupagem, que determina cada ação, isto é, cada intenção, este trabalho de respiração leva o ator a ter e fazer com mais clareza cada momento.

A respiração traz a energia cênica. Existe uma técnica de atuação que utiliza muito a respiração, que tem como exemplo bem claro o ator Francisco Cuoco, que tem uma fala cênica utilizando muito ar, isto é, a sua respiração é perceptível enquanto fala.

Um exemplo bem simples em que aparece a força da respiração no sentido proposto, e que talvez todos nós já tenhamos experimentado, ocorreu comigo quando jovem, em torno dos 13 anos, dançando junto com a garota que eu estava interessado. Eu estava inseguro se ela também estava interessada em mim. Então, para checar o seu interesse, eu inspirei com a intenção de falar com ela sem me descolar dela. Ela rapidamente recuou para me olhar, se disponibilizando para me escutar. Ela estava interessada! Eu não precisei fazer o movimento para falar, mas apenas inspirei com a intenção de falar. A utilização da respiração consciente ajuda muito no foco da cena, procedimento que discorrerei mais adiante.

A mímica trabalha com a síntese dos gestos, do movimento, da ação. A este terceiro procedimento chamei de economia de movimento. Para cada intenção definida na decupagem, foi encontrado um "copião" de cena, e então se estuda o mínimo de ações que são necessárias para representá-la. Dario Fo comentando sobre os excessos de alguns mimos, diz: "Portanto, precisamos aprender a jogar fora todo o supérfluo, o que significa economia e, novamente, síntese e estilo." (FO, 2004, p.272),

Peter Brook também contribui para este pensamento quando diz: "O vazio no teatro permite que a imaginação preencha as lacunas. Paradoxalmente, quanto menos se oferece à imaginação, mais feliz ela fica, porque é como um músculo que gosta de se exercitar em jogos." (BROOK, 1999, p.23) 
Esta intenção da mímica de criar o essencial como forma poética, mas que também é do teatro físico e de tantas outras formas teatrais, convida o público a ser um coautor do espetáculo, preenchendo com a sua imaginação todas as lacunas oferecidas, criando e dando nexo, cada qual, à sua própria história. Dario Fo diz: "A arte do mimo é a arte da comunicação com síntese. Não se trata de imitar literalmente as gestualidades naturais, como já observei em outras ocasiões, mas de sugerir, indicar, subentender, fazer imaginar." (FO, 2004, p. 269)

Portanto, estamos falando de uma atitude do mimo/ator em cena, de ter uma intenção de sugerir, propor que o público imagine, crie com a sua imaginação. Isto quer dizer que no momento da apresentação a busca do mimo/ator não é criar uma ilusão, mas induzir o público a fazê-lo.

O último procedimento é o foco. Foco é o ponto para onde deve convergir a atenção de todos. Viola Spolin define como a "atenção dirigida e concentrada numa pessoa, objeto ou acontecimento (...)" (SPOLIN, 1986, p.340). Na cena, foco é o que conta a história ${ }^{5}$. Na maioria das vezes é o ator, mas pode ser um objeto, a coxia etc. No ator, foco é a parte de seu corpo que conta a história. Para isso, é necessário que se desenvolva a consciência corporal. Técnicas da mímica fazem com que o ator realize o foco com maior precisão.

Para que se compreenda melhor é desenvolvido um exercício que explicita quem está com o foco da cena. $O$ exercício é o seguinte: os atores fazem um ensaio completo jogando uma bolinha de tênis um para o outro. Quem está com o foco, está com a bolinha. A bolinha representa o olhar da plateia, isto é, a plateia vai olhar para quem está com a bolinha. Também o outro ator tem que estar com a sua atenção no ator com a bolinha. Estou falando do ator e não da personagem. A personagem tem seu caminho próprio. Mas o ator tem que pôr a sua atenção no foco. O exercício da bolinha é importante porque deixa claro para o ator onde deve estar o foco da cena. Eventualmente o foco pode estar em um objeto, fora de cena etc.

Este procedimento pressupõe a compreensão do que é neutralidade em mímica. É a minimização da história presente no corpo do artista, sob o pressuposto de que tudo o que vivemos não será jamais apagado. Fazendo uma analogia com cores temos: a história é como traços coloridos no corpo e o trabalho de conscientização vai minimizando

5 Se vários personagens estão agindo ao mesmo tempo, isto gera uma confusão na leitura pelo público. Esta pode ser uma opção estética, isto é, a escolha é intencional. 
esses traços, transformando-os em cores pastéis. Ao construir uma personagem, o mimo escolhe as cores pertinentes e torna a tingir em cores fortes, isto é, amplia as suas características pessoais que se referem às da personagem. Quando se olha de longe se vê, praticamente, só as cores fortes, pois as cores pastéis parecerão brancas.

O ator que não está com o foco deve fazer a sua ação com certa neutralidade. Isto quer dizer que a ação vai contar somente sobre ela própria, é a ação sem adjetivos. Por exemplo, se ele está olhando para o ator que está com o foco, se pretende que a plateia deva ler "ele está olhando para o outro". Enquanto o foco está no outro, não há espaço para comentários corporais do ator do tipo "estou gostando", ou "não estou concordando". O ator deve esperar estar com o foco para fazer o comentário. O foco pode estar em mais de um ator ao mesmo tempo, como no momento da briga em que as personagens se agarram.

O foco também pode ser usado em relação à parte do corpo do ator que está contando a história. Por exemplo, quando a fala é a essência do que se quer contar, o ator não deve se mexer, nem gesticular. Também é possível colocar o foco do movimento no tórax, na altura do coração. Com isso possibilitar a leitura de que se está apaixonado. O foco pode estar na composição criada pelo ator, já que a fala e a ação não precisam contar a mesma coisa, e sim compor uma intenção com maior complexidade. O grau de utilização deste enfoque depende do grau de domínio da técnica da mímica ou similar.

$\mathrm{Na}$ tese, ao final do processo de montagem, os três participantes - René, Roberto e Eduardo - deram seus relatos juntos. René, com sua visão de diretor, disse que descobriu essa possibilidade de, mesmo dentro de um registro realista, conseguir chegar a uma partitura, a uma precisão, a uma limpeza de cena. Ele esteve ausente em alguns ensaios e, quando voltou, notou que o espetáculo estava mais limpo. Ainda afirmou que a percepção por parte do público, de quem está de fora, ficou muito mais clara. E sem precisar abrir mão das escolhas todas. Quer dizer, que é possível pegar uma cena onde as opções estéticas já estão determinadas, e fazer um trabalho, esse segundo momento, de limpeza. Roberto também colocou, pela visão de ator, que este caminho não está vinculado a uma determinada estética teatral. Ele comentou de uma dificuldade com o texto que perdurou até que descobrisse que poderia ter outra razão para dizer aquelas falas. Que tinha uma ação da personagem que precisava ser descoberta. Que essa descoberta é parte do processo de criação da cena. E que, aos 
poucos, isso foi sendo feito. Roberto também colocou que a decupagem era em cima de ações, movimentos já propostos, mas que muitas vezes não eram repetidas pelos atores. Que o fato de eu questionar o que ele queria dizer com aquela determinada ação, fazia com que ele tivesse que parar, pensar para definir o que queria dizer exatamente. Para isso, é preciso olhar para si, ver o que você se quer dizer.

Este meu questionamento é fundamental para que o ator se coloque e, consequentemente, tenha maior consciência da sua proposição para a cena. Com isso, dificulto o caminho fácil em que o ator faz ações prontas, que não foram encontradas dentro daquele processo de montagem. É como Dario Fo diz: "Em teatro, o gesto precisa ser reinventado, do mesmo modo como se reinventam as palavras. É necessário aprender a partir da realidade, não das convenções da realidade." (FO, 2004, p.269)

Com o desenvolvimento da partitura física Roberto disse que ele conseguiu repetir as ações, com todos os seus detalhes, porque existia um caminho, um passo a passo para o ator percorrer. Para ele, dentro daquele caminho o ator cria possibilidades de emoções, que vieram à tona no decorrer das improvisações. É como se o ator adquirisse uma liberdade grande de estar improvisando dentro de coisas marcadas. No que concordou Eduardo, o outro ator, ao dizer que não sentiu como rigidez o trabalho de decupar milimetricamente a cena, pois que não cerceia a criatividade, não prende o ator na marca, que pode criar outra forma. Mas que, por ter essas marcas, ele se sentia seguro, que lhe dava um chão, e que acaba por ajudar a ter outras ideias. Eduardo reforçou a ideia de segurança quando disse que ele não ficou perdido em cena, pois tinha onde se segurar quando não estava inspirado. Portanto, que existe um mínimo que possibilita que o espetáculo tenha sempre qualidade. Essa preocupação com a qualidade do espetáculo também foi colocado por Roberto ao dizer sobre a possibilidade do ator ter a prerrogativa de dar mais ou menos acento às suas ações, esta liberdade de escolha, o que gerou para ele, aos poucos, muito prazer em atuar. Mesmo em trechos de falas longas, ao final do processo ele já se sentia tranquilo em executá-las, por ter uma verdade física, corporal.

Este estado de segurança, tranquilidade e prazer são fundamentais para o fazer teatral. No último ensaio desta fase, pedi aos atores que fizessem algumas cenas apenas com a preocupação de executá-las tecnicamente, pensando nos procedimentos, deixando de lado as emoções das personagens. As cenas ficaram ótimas teatralmente. E René, lembrando deste episódio, comentou sobre o fato do ator pensar 
que está sendo frio, que consequentemente não está comunicando, mas que na verdade, pra quem está de fora, resulta muito cenicamente. O que Eduardo tentou explicar dizendo que a decupagem impossibilita o ator fazer sem emoção. Quer dizer, que a ação física já traz a intenção como um todo. Ele comentou que se arrepiava de verdade em quase todas as vezes em que passava a cena final, apesar de não estar procurando ficar arrepiado. Mas ficava! E que sobre a ação física o ator tem mais controle do que sobre o 'vou me emocionar, vou ter uma memória emotiva'. Roberto vai por outro caminho. Para ele é muito bom ter definido as intenções essenciais e procurar recursos físicos para representá-las, porque dá uma base externa. Que é bom quando o ator tem consciência da sua ação que é visível, que é concreta, para que ele possa de vez em quando alcançar o impalpável, o inconcreto, o emocional...

Dario Fo, ao discorrer sobre o mimo e a pantomima, explica: "Por convenção, indica-se o verbo mimar uma ação gestual capaz de produzir um discurso ou narrar uma história sem o uso das palavras." (FO, 2004, p. 267) Partindo deste conceito de Fo, a partitura criada pelos atores é a forma como eles estão mimando o espetáculo. Roberto disse que ficou bem claro que era dele a cena, pessoal, que partiu do texto escrito, mas que ao final era o texto do espetáculo criado por todos. O resultado desta partitura no espetáculo é detectado por René:

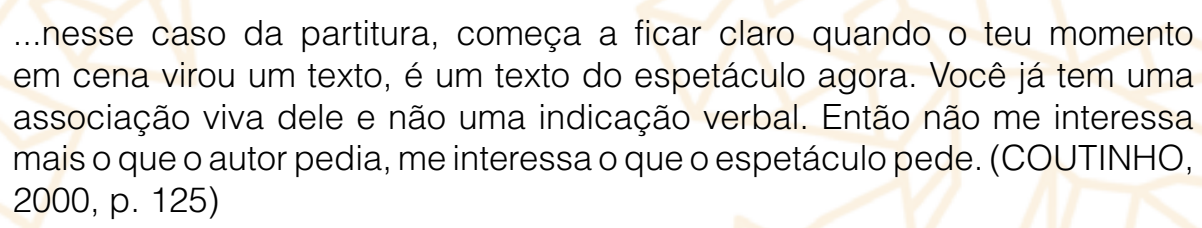

Essa experiência na pesquisa trouxe reflexões também por parte dos atores. Eduardo trouxe a sensação de atuar em outro espetáculo, que está em cartaz, sem ter feito este trabalho:

Eu me senti sujo porque estou jogando um monte de coisa fora, estou sujando tudo, estou fazendo milhões de coisas. Eu poderia estar escolhendo melhor e direcionando melhor essas ações nos outros trabalhos. (COUTINHO, 2000, p. 126)

Roberto fala do ofício do ator:

... esse caminho acaba possibilitando ampliar um pouco a ação de dizer do ator. Verbaliza uma coisa mas, ao mesmo tempo, ele gera impressões diversas, que não exatamente aquilo que ele está dizendo. Eu acho que esse caminho tem possibilitado um pouco isso. $\mathrm{E}$ a consciência disso é muito legal, porque ela não inibe. Ela libera! (COUTINHO, 2000, p. 126) 


\section{Considerações Finais}

Os relatos de René, Roberto e Eduardo e Juliana, trazem os bons frutos resultantes de suas vivências com esta abordagem. René possui a visão do diretor, falando de estética, da limpeza de cena e do resultado para quem assiste. Além disso, ressalta que este trabalho não impõe uma estética ao espetáculo. Mas cria um texto do espetáculo, resultado indissociável do texto escrito com o texto das ações físicas. Meyerhold é enfático quando diz: "A pantomima fecha a porta para o retórico e o lugar deste é numa cátedra e não no teatro. Pelo contrário, o jogral afirma a arte do ator que se basta; sem se limitar à oratória, o gesto e a linguagem dos movimentos exprimem-se em situações cênicas." (In ALDOMAR CONRADO, 1969, p.86)

Os atores relatam as suas experiências de um processo teatral com ênfase no corpo, descobrindo e reafirmando princípios do ofício do ator. No começo era difícil, mas aos poucos eles foram dominando a técnica. As palavras usadas em seus relatos para essa experiência foram: tranquilidade, prazer, segurança, liberdade. Juliana fala da liberdade de criar a partir dos estímulos dados dentro do processo, Eduardo pôde até fazer uma autocrítica sobre seu desempenho como ator em outro espetáculo em que atuou em seguida. E Roberto entende que este trabalho fortalece a atividade do ator, ampliando o seu canal de comunicação com a plateia e possibilitando maior espaço do ator na criação do espetáculo teatral.

Portanto, os procedimentos contribuem para a arte de ator, com seu ofício, criando uma dramaturgia de ator, com a melhora na sua qualidade artística, com a ampliação do seu espaço na criação teatral, além de oferecer um instrumental técnico de ator para o desenvolvimento da linguagem teatral.

\section{Referências Bibliográficas}

BROOK, Peter. A porta aberta. Rio de Janeiro: Civilização Brasileira, 1999.

CONRADO, Aldomar. O teatro de Meyerhold. Rio de Janeiro: Civilização Brasileira, 1969.

COUTINHO, Eduardo T. Uma Cena Precisa. Procedimentos para uma cena quase pronta. São Paulo, 2000. Tese (doutorado) ECA-USP.

DECROUX, Étienne. Parole sur le mime, ga ed. Paris: Gallimard, 1963.

FO, Dario. Manual Mínimo do Ator. São Paulo. Ed. Senac, 2004.

HAUSBRANDT, Andrzej. Tomaszewski's mime theatre. Warsaw: Interpress Publication, 1975. SPOLIN, Viola. Improvisação para o teatro. São Paulo: Perspectiva, 1986. 